\title{
Mixed news for doctors as feds pivot on tax reforms
}

Cite as: CMAJ 2017 November 6;189:E1371. doi: 10.1503/cmaj.109-5515

Posted on cmajnews.com on Oct. 16, 2017.

$\mathrm{T}$ he federal government is forging ahead with some, but not all, of a suite of controversial tax reforms that many doctors say will undercut their financial stability.

Prime Minister Justin Trudeau and Finance Minister Bill Morneau announced Monday that the government is going forward with its plan to limit income sprinkling - that is, when a high earner uses a corporation to divert income to family members who are taxed at lower rates, regardless of whether they actually work for the company.

"It just isn't fair for some companies or individuals to be able to take advantage of income sprinkling when others cannot because their kids are the wrong age or they're not married," Trudeau told reporters.

The government will make an exception for business owners who can prove their family members "meaningfully contribute" to their companies, he added. For such cases, "we are going to make sure there's a simple and clear framework."

The government will not proceed with a proposal to limit access to the lifetime capital gains exemption, which allows business owners to shelter up to $\$ 835716$ in lifetime income for each shareholder in a company (usually family members). This retains an important benefit of incorporation for physicians, many of whom say they use this strategy to save for retirement.

Trudeau also committed to cut the small business tax rate from $10.5 \%$ to $9 \%$.

The pivot comes after intense backlash from small business owners, including doctors, who in some provinces won the right to incorporate in lieu of other benefits. Many doctors also criticized the gov-

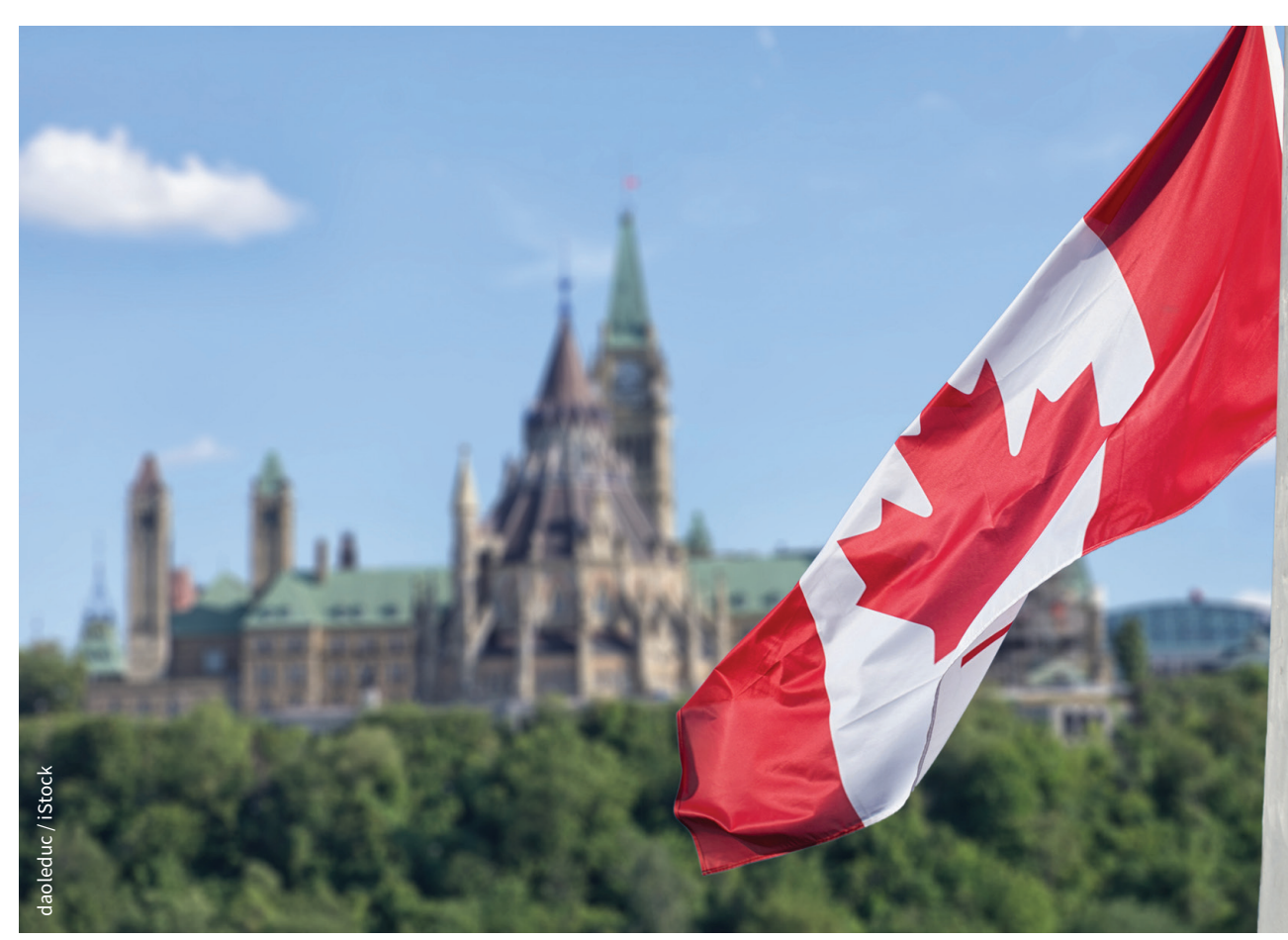

Income sprinkling reforms will go ahead, but access to lifetime capital gains exemption won't change.

ernment for using rhetoric that framed the use of legal tax strategies as cheating.

A third proposal to neutralize the tax advantages of holding passive investments in a corporation was not addressed. However, Trudeau said there are more announcements coming shortly.

\section{Lauren Vogel, CMAJ}

